\title{
Adjusted EPOP as an Indicator of Labor Market Strength
}

\author{
Julie L. Hotchkiss ${ }^{1, *}$ \\ ${ }^{1}$ Federal Reserve Bank of Atlanta and Georgia State University, Atlanta, GA 30309, United \\ States \\ *Correspondence: Federal Reserve Bank of Atlanta, 1000 Peachtree St. NE, Atlanta, GA \\ 30309, United States. Tel: 1-404-498-8198. E-mail: Julie.L.Hotchkiss@atl.frb.org
}

Received: August 25, 2014 Accepted: September 17, 2014 Published: September 27, 2014

doi:10.5296/rae.v6i3.6364 URL: http://dx.doi.org/10.5296/rae.v6i3.6364

\begin{abstract}
As a measure of labor market strength, the raw Employment-to-Population ratio (EPOP) confounds employment outcomes with labor supply behavior. Movement in the EPOP depends on the relative movements of the employment rate (one minus the unemployment rate) and the labor force participation rate. This paper proposes an adjustment to the calculation of the EPOP, using individual micro data to account for both individual characteristics and the probability of labor force participation, which can be used to assess the strength of the labor market. The adjusted EPOP confirms what we already knew-that the stagnation of the EPOP since the end of the Great Recession is the result of continued declines in the labor force participation rate. Stripping the EPOP of confounding changes in labor supply we uncover a story that is more consistent with movements in the unemployment rate-the adjusted EPOP has regained its prerecession level of nearly 63 percent. Youth have regained even more, and those 25 to 54 regained 71 percent of their loss over the sample period. Of course, there remains the issue of declining labor force participation, which is a legitimate but different concern than whether the labor market is providing enough jobs.
\end{abstract}

Keywords: Employment-to-population ratio, Labor force participation, Employment rate, Unemployment rate, Full employment 


\section{Introduction}

In conjunction with the number of new payroll jobs generated, the unemployment rate (UR) is eagerly anticipated each month as arguably the most important measure of the strength of the labor market. The $U R$ indicates what percent of the labor force (those who want jobs) is unable to find a job. In a strong labor market, the $U R$ declines, suggesting movement toward full employment. Even the Federal Reserve, in pursuit of its dual mandate of stable prices and maximum employment, relies heavily on the $U R$ as an indicator of movement toward maximum employment. Use of the $U R$ acknowledges that a sustainable notion of maximum employment has to somehow take into account the willingness of individuals to work.

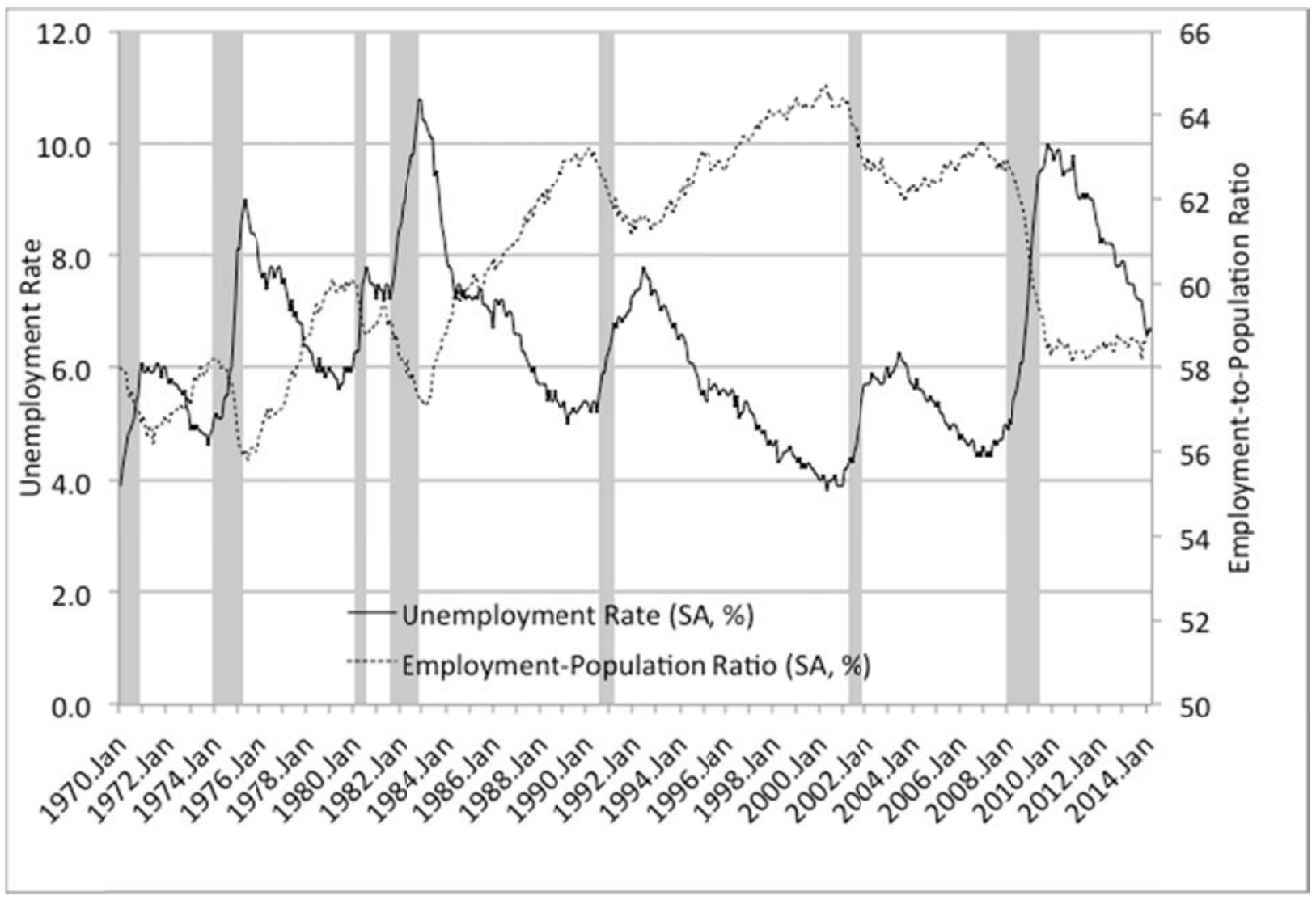

Figure 1. The Unemployment Rate and Employment-to-Population Ratio, Jan. 1970-March 2014

Note: Gray bars reflect recessionary periods.

In the post-Great Recession economy, however, there have been calls to pay closer attention to the movement in the employment-to-population ratio (EPOP), as opposed to the $U R$, as a measure of labor market strength. (Note 1) As can be seen in Figure 1, which of these statistics one focused on was a nonissue prior to the Great Recession-the EPOP and the UR moved in almost perfect (inverse) lockstep with each other. Since the end of the Great Recession, however, there appears to be a disconnect; the $U R$ has fallen dramatically, indicating a strengthening of the labor market, but the EPOP has barely budged, suggesting to some that the $U R$ is no longer a useful indicator of labor market strength. The purpose of 
this paper is not to argue for the use of the UR over EPOP as an indicator of labor market strength, but rather, propose a methodology for adjusting the EPOP in a way that accounts for individual willingness to work. The unadjusted EPOP may still be preferred when assessing resource utilization of the nation's human capital. (Note 2) But as a measure of labor market strength, the adjusted EPOP provides a more accurate picture.

\section{The EPOP Decomposed}

As a raw statistic, the EPOP reflects the percent of the total population (POP) (or some segment of the population of interest) that is employed $(E)$. The EPOP can also be expressed as the product of the employment rate ( $E R$, or one minus the unemployment rate) and the labor force participation rate $(L F P R)$, which is the total labor force $(L F)$ divided by the population:

$$
E P O P_{t}=\frac{E_{t}}{P O P_{t}}=\frac{E_{t}}{L F_{t}} \times \frac{L F_{t}}{P O P_{t}}=E R_{t} \times L F P R_{t} .(\text { Note 3) }
$$

The direction and relative movements of $E R$ and $L F P R$ will dictate in what direction the EPOP will move. This decomposition makes it clear that movements in the EPOP can be driven by movements in the $L F P R$, rather than by movements in the $E R$.

In order to be employed, one must want/seek a job. Ignoring changes in labor force participation (stemming either from changes in demographics or changes in behavior) biases the EPOP as a measure of labor market strength. In other words, the probability of anyone in the population having a job is not the statistic of interest for determining labor market strength, but rather, the probability of anyone in the population who wants a job is. That's the appeal of the $U R$-it indicates the share of those who want jobs who are unable to find one. This paper proposes a methodology to adjust the probability of employment within the population by the probability of being a labor force participant (wanting a job) in order to obtain an adjustment to the EPOP with which to assess labor market strength. Relying merely on the raw EPOP confounds movement in the probability of employment with movements in labor force participation.

Movement in the adjusted EPOP proposed here closely follows movement in the employment rate $(E R)$, since the $E R$ conditions the employment outcome (through selection) on labor force participation. The advantage of modeling movement in the EPOP, as opposed to modeling movement in the $E R$, is the ability to disentangle movements in individual demographics and labor supply behavior from employment outcomes at the population level (not merely among those in the labor force). (Note 4) The analysis doesn't tell us anything we didn't already know from the decomposition above-the stagnation in the EPOP since the Great Recession results from labor force participation falling at the same rate as the employment rate is rising. However, the adjusted EPOP does give us a measure of labor market strength stripped of confounding labor supply decisions that suggests employment probabilities are back up to prerecession levels. 


\section{Modeling EPOP}

The basic strategy of modeling EPOP so that it can be used as an indicator of labor market strength is to estimate individual probability of employment as a function of month/year indicators, then to enhance the model, first with individual characteristics and then with the individual's propensity to be in the labor force. The coefficients on the month/year indicators from the unadjusted model closely fit the raw EPOP statistic. However, these coefficients, as indicators of population employment outcomes, or labor market strength, can be viewed as suffering from omitted variable bias, as all of the individual characteristics and the individual's probability of labor force participation remain in the error term and are arguably significantly correlated with the month/year indicators of EPOP. (Note 5) After describing the data used for the analysis, details of the modeling process will be presented.

\subsection{The Data}

The monthly Current Population Survey (CPS) from November 1999 through December 2013 is used to obtain demographic and labor market information related to the civilian noninstitutional 16-years-and-older population in the United States. Roughly 60000 households are interviewed each month and provide information about labor market (and other) activity during the week that includes the 12th of the month. Responses to this survey are used by the U.S. Bureau of Labor Statistics (BLS) to report the national employment situation for households, including the official $U R$, each month. Using the basic population weight, these national statistics can be replicated fairly accurately. (Note 6)

Figure 2 illustrates the $E P O P$, the $U R$, and the labor force participation rate $(L F P R)$ reported by the BLS each month from November 1999 through December 2013, along with the same series constructed using the weighted monthly CPS survey data that are used for the analysis in this paper. Figure 2 illustrates that we are able to replicate the officially reported series very closely.

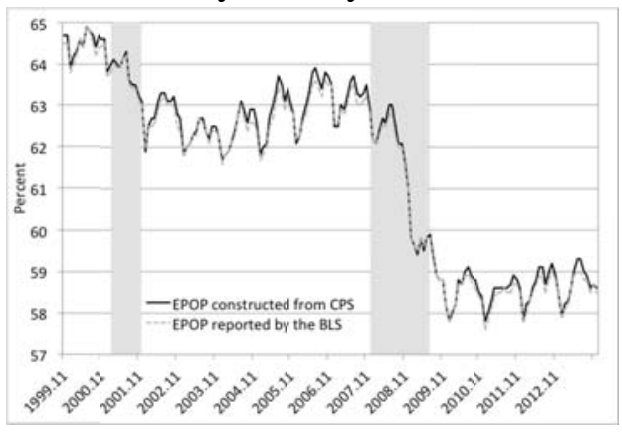

Panel (a): EPOP

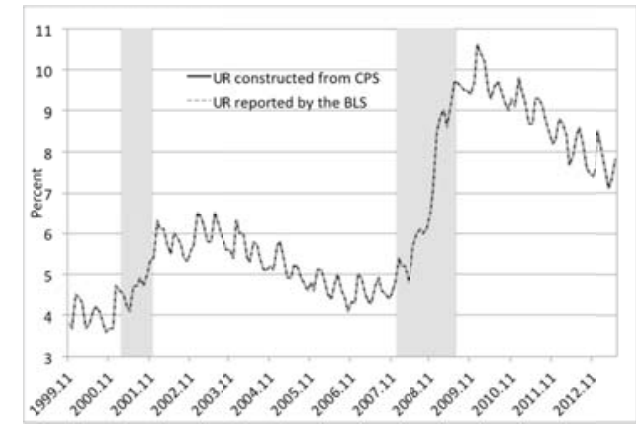

Panel (b): The $U R$

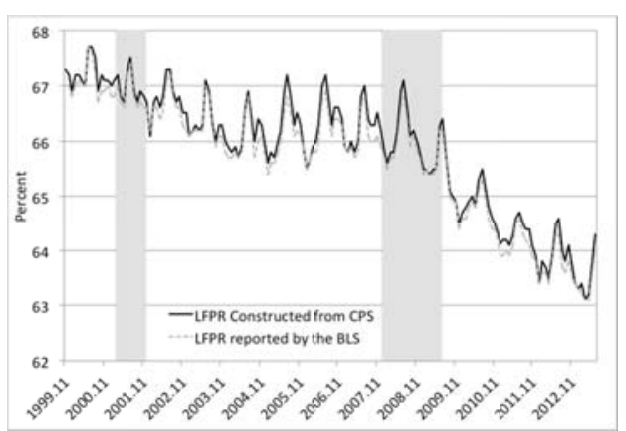

Panel (c): The LFPR

Figure 2. Comparing CPS Survey Data with Official BLS Reported Statistics, November 1999 through December 2013.

Note: Gray bars reflect recessionary periods. November 1999 is the first month used for the analysis in this paper since it is the first month in which an important regressor need for estimation is available. 


\subsection{The Basic Model}

The EPOP in any given month is merely the average number of people in the population who are employed. This differs from the $U R$, or the employment rate $(E R)$, in that the denominator in the calculation is the population, rather than the labor force. In other words, the EPOP in time period $t$ for a population of size $N_{\text {pop }}$ is simply calculated as follows:

$$
E P O P_{t}=\frac{1}{N_{\text {pop }}} \sum_{i=1}^{N_{\text {pop }}} E M P_{i t},
$$

where $E M P_{i t}=1$ if person $i$ is employed at time $t, 0$ otherwise. EPOP can be thought of as the average joint probability of employment and labor force participation within the population. It is the joint probability because observing someone as employed necessarily requires that a person has first decided he or she wants a job (i.e., is in the labor force).

The aggregate EPOP can also be generated in a regression framework by modeling individual (i) employment at time $t, E M P_{i t}$, as a function of a set of month/year time indicators, $m y_{t}$, as follows: (Note 7)

$$
E M P_{i t}=\delta_{1}+\sum_{t=2}^{T} \delta_{t} m y_{t}+e_{i t}
$$

Aggregate $E P O P_{t}$ is then constructed by adding $\hat{\delta}_{t}, t=2$ to $\mathrm{T}$, to the raw, observed EPOP value for $t=1$. The result is depicted in Figure 3, panel (a); with some minor deviations, the estimated month/year indicator coefficients reflect the average of $E M P_{i t}$ in any given time period, which is simply the nonseasonally adjusted $E P O P_{t}$ (see equation 2).

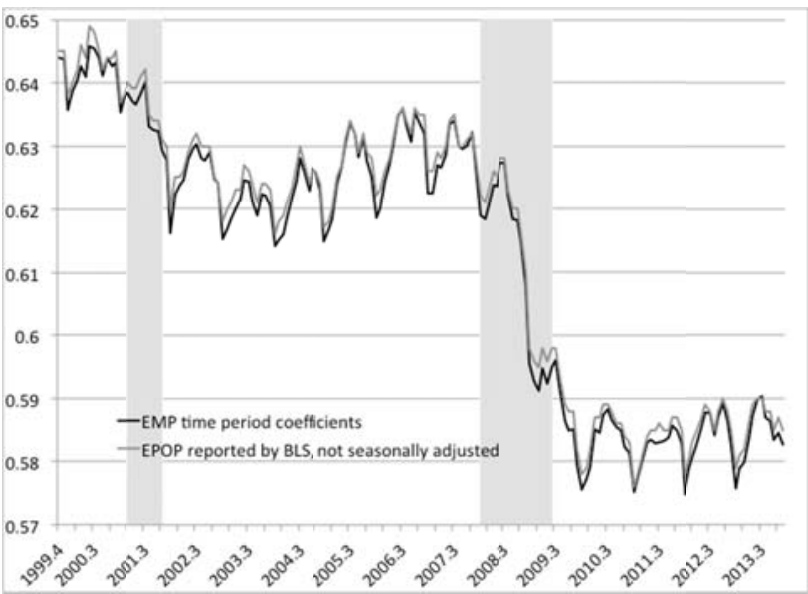

Panel (a): Nonseasonally adjusted

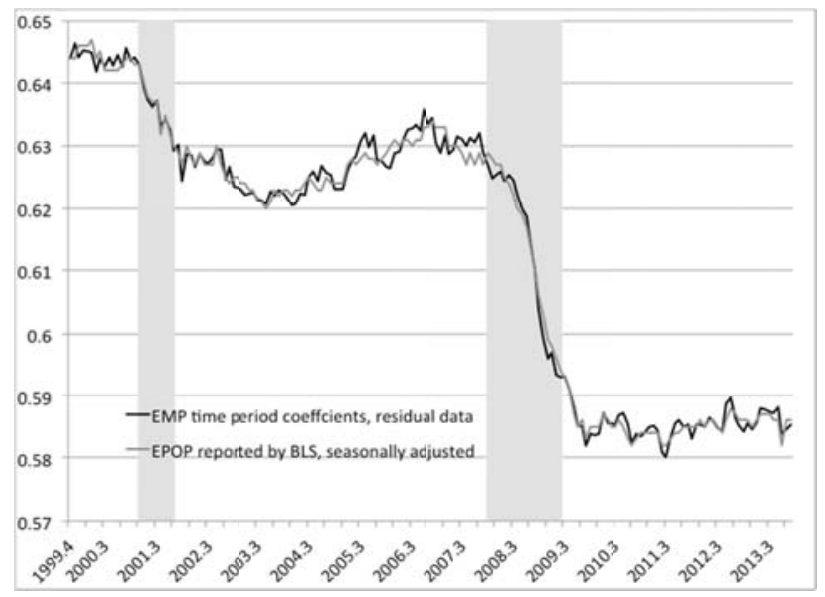

Panel (b): Seasonally adjusted

Figure 3. Estimated Coefficients from Month/Year Indicators in a Linear Employment Probability Regression and the EPOP reported by the BLS, November 1999 through

December 2013.

Note: Gray bars reflect recessionary periods.

All estimations here are performed using the raw population weights provided by the CPS. As the population grows over time, this has the effect of weighting later observations more than earlier observations in a regression over time. Adjusting the weights so that they add up to the same number in each month has no appreciable effect on the results. The effect of doing this is illustrated in the Appendix. (Note 8) 
In order to remove seasonality from the dynamics of the EPOP construction, the raw individual employment data are transformed through a residual approach. In other words, the residuals obtained from first regressing the observed individual employment outcomes $\left(E M P_{i t}=0,1\right)$ on monthly indicators are used as the dependent variable in the linear employment probability model:

$$
E M P_{-} R_{i t}=\alpha+\sum_{t=2}^{T} \delta_{t} m y_{t}+e_{i t} .
$$

The residual from regressing $E M P_{i t}$ on monthly indicators only is what is left over of the individual's probability of employment after removing monthly variation. The result of this deseasonalization approach can be seen in Figure 3, panel (b). The parameter coefficients still closely follow the actual, now seasonally adjusted, EPOP reported by the BLS. (Note 9)

\subsection{The Adjusted Model}

Interpreting period estimates from equation (3') as indicators of labor market strength, or as employment probabilities rather than as joint employment/participation probabilities, requires that the error term is uncorrelated with the month/year indicators. Since each person in the population varies in characteristics that predictably either improve or hamper his/her probability of employment, and because a person's probability of employment is necessarily correlated with his/her labor force participation decision, the raw EPOP statistic (or $E M P_{-} R_{i t}$ coefficients estimated using month/year indicators alone) suffers from omitted variable bias and will not reflect the probability of employment for an individual in the population. (Note 10) In other words, the error term in equation (3') is more accurately expressed as follows:

$$
e_{i t}=\Omega^{\prime} X_{i t}+\gamma L F P_{i t}^{*}+\varepsilon_{i t},
$$

where $X_{i t}$ are individual characteristics, $L F P_{i t}^{*}$ is individual $i$ 's unobserved propensity to participate in the labor market at time $t$, and $\varepsilon_{i t}$ is a random component uncorrelated with $m y_{t}$ (or $X_{i t}$ or $L F P_{i t}^{*}$ ).

If the correlation between the omitted variables in equation (4) and $m y_{t}$ is nonzero, then $\delta_{t}$ (in equation 3') will be biased. More specifically, the stronger the correlation (which appears to be relevant in the most recent time period), the greater the deviation of $e_{i t}$ from $\varepsilon_{i t}$, and the more biased will be $\delta_{t}$. Through and since the Great Recession, the population has undergone particularly dramatic changes in demographics and labor supply behavior (for example, see Hotchkiss and Rios-Avila 2013 and Aaronson 2012), increasing the chances for bias in $\delta_{t}$.

To be clear, if one wants an estimate of the joint probability of employment and labor force participation, then $\hat{\delta}_{t}$ obtained from estimating equation (3) is unbiased. However, if one wants an estimate of employment probability reflecting labor market strength, then the omitted variables need to come out of the error term. (Note 11)

Bringing observed characteristics (such as age and education) out of the error term is straightforward; they are known and simply included as additional regressors in the estimating equation. Controlling for an individual's unobserved propensity to be in the labor 
market is a little more complicated. Since $L F P_{i t}^{*}$ is unobserved, we need to construct a proxy. To do so, the following linear probability model is estimated:

$$
L F P_{-} R_{i t}=\beta+\sum_{t=2}^{T} \theta_{t} m y_{t}+\Pi^{\prime} X_{i t}+\Gamma^{\prime} Y_{i t}+v_{i t},
$$

where all terms are as defined above and $L F P_{-} R_{i t}$ is seasonally adjusted (as described above, using the residual approach) observed individual labor force participation and $Y_{i t}$ are determinants of the individual's labor force participation decision that are not expected to affect the individual's employment outcome.

An exclusion variable $\left(Y_{i t}\right)$ is required in order to be able to identify the month/year (and $X_{i t}$ ) coefficients in the employment equation. Typical candidates for such an exclusion variable in the determination of labor supply are the individual's number of children and nonlabor income. Both of these characteristics are theorized to affect one's reservation wage (minimum wage required to enter the labor force), but not to affect one's market wage, hence employment outcomes. Because of the limitations of the basic CPS Survey (monthly), we only have the individual's number of children available as an exclusion variable. (Note 12) As a rough idea about the relative empirical importance of the number of children for labor force participation and employment outcomes, we calculated simple correlation coefficients (for those aged 18 to 54 due to the timing of raising a family and work life). The correlations between number of children and labor force participation and employment are -0.02 and -0.005 , respectively. In addition, number of children is a significant determinant of labor force participation decisions (see estimation results in Table 1).

The predicted value of $L F P_{-} R_{i t}$ is then included as an additional regressor in the employment equation:

$$
E M P_{-} R_{i t}=\alpha+\sum_{t=2}^{T} \delta_{t} m y_{t}+\Omega^{\prime} X_{i t}+\gamma \widehat{L F P_{-}} R_{i t}+\varepsilon_{i t} .
$$

The estimated $\delta_{t}$ coefficients obtained from equation (6) will be free from bias, subject to the assumptions stated above, and yield an adjusted calculation of the EPOP that does not confound the population average individual probability of employment with individual characteristics or individual probability of labor force participation. (Note 13)

\section{Estimation Results}

Table 1 reports the estimated parameter coefficients from estimating equations (5) and (6). Comparing the parameter estimates in columns two and three illustrate how biased the parameter estimates in the employment equation are when an individual's labor force participation probability is not accounted for in the regression (i.e., left in the error term). For example, it's clear that the lower observed joint employment/LFP probability (column 3) among women is driven by the significantly lower probability of women to participate in the labor market. In addition, the higher observed probability of joint employment/LFP among Hispanics is being driven by their higher probability of participating in the labor force, ceteris paribus, and that participation behavior is driving much of the difference in employment/LFP outcomes across education groups. While not shown here, these same sorts of biases exist in 
the estimates of the month/year indicator coefficients when labor force participation is excluded from the employment equation. The importance of the labor force participation decision in the employment outcome is also seen in the estimated coefficient on $\overline{L F P_{-}} R_{i t}$. That coefficient tells us that a 0.10 percentage point increase in a person's likelihood of participating in the labor market increases his/her probability of employment by 0.14 percentage points - this "multiplier" effect of the decision to be in the labor force reflects the fact that being in the labor force is a necessary condition to being employed.

Table 1. Linear Probability Estimates from Two-Step Estimation of Labor Force Participation and Employment

\begin{tabular}{|c|c|c|c|}
\hline Regressors & $\begin{array}{c}\text { LFP_R } \\
\text { equation (5) } \\
(1)\end{array}$ & $\begin{array}{c}\text { EMP_R } \\
\text { equation (6) } \\
(2)\end{array}$ & $\begin{array}{c}\text { EMP_R } \\
\text { equation (6) } \\
\text { excluding } \widehat{L F P}_{\text {it }} \\
\text { (3) }\end{array}$ \\
\hline age & $\begin{array}{l}0.0370 * * * \\
(0.00004)\end{array}$ & $\begin{array}{l}-0.0152 * \\
(0.0079)\end{array}$ & $\begin{array}{l}0.0370 * * * \\
(0.00004)\end{array}$ \\
\hline age2 & $\begin{array}{l}-0.0005 * * * \\
(0.0000003)\end{array}$ & $\begin{array}{l}0.0002 * * \\
(0.0001)\end{array}$ & $\begin{array}{l}-0.0005 * * * \\
(0.0000004)\end{array}$ \\
\hline female & $\begin{array}{l}-0.1136 * * * \\
(0.0002)\end{array}$ & $\begin{array}{l}0.0585^{* *} \\
(0.242)\end{array}$ & $\begin{array}{l}-0.1020 * * * \\
(0.0002)\end{array}$ \\
\hline married_sp & $\begin{array}{l}-0.0091 * * * \\
(0.0003)\end{array}$ & $\begin{array}{l}0.0237 * * * \\
(0.0020)\end{array}$ & $\begin{array}{l}0.0102^{* * *} \\
(0.0003)\end{array}$ \\
\hline black & $\begin{array}{l}-0.0333^{* * *} \\
(0.0004)\end{array}$ & $\begin{array}{l}-0.0138^{*} \\
(0.0071)\end{array}$ & $\begin{array}{l}-0.0610 * * * \\
(0.0004)\end{array}$ \\
\hline othrace & $\begin{array}{l}-0.0480 * * * \\
(0.0005)\end{array}$ & $\begin{array}{l}0.0184 * \\
(0.0102)\end{array}$ & $\begin{array}{l}-0.0494 * * * \\
(0.0005)\end{array}$ \\
\hline hispanic & $\begin{array}{l}0.0237 * * * \\
(0.0004)\end{array}$ & $\begin{array}{l}-0.0151^{* * *} \\
(0.0050)\end{array}$ & $\begin{array}{l}0.0182 * * * \\
(0.0004)\end{array}$ \\
\hline hs & $\begin{array}{l}0.1492 * * * \\
(0.0004)\end{array}$ & $\begin{array}{l}-0.0602^{*} \\
(0.0318)\end{array}$ & $\begin{array}{l}0.1505^{* * *} \\
(0.0004)\end{array}$ \\
\hline scoll & $\begin{array}{l}0.1850 * * * \\
(0.0004)\end{array}$ & $\begin{array}{l}-0.0634 \\
(0.0394)\end{array}$ & $\begin{array}{l}0.1979 * * * \\
(0.0004)\end{array}$ \\
\hline ba & $\begin{array}{l}0.2324 * * * \\
(0.0004)\end{array}$ & $\begin{array}{l}-0.0748 \\
(0.0495)\end{array}$ & $\begin{array}{l}0.2535 * * * \\
(0.0004)\end{array}$ \\
\hline grad & $\begin{array}{l}0.2628 * * * \\
(0.0005)\end{array}$ & $\begin{array}{l}-0.0839 \\
(0.0560)\end{array}$ & $\begin{array}{l}0.2873 * * * \\
(0.0005)\end{array}$ \\
\hline mw & $\begin{array}{l}0.0239 * * * \\
(0.0003)\end{array}$ & $\begin{array}{l}-0.0136^{* * *} \\
(0.0051)\end{array}$ & $\begin{array}{l}0.0201 * * * \\
(0.0003)\end{array}$ \\
\hline south & $\begin{array}{l}-0.0035^{* * *} \\
(0.0003)\end{array}$ & $\begin{array}{l}0.0043^{* * *} \\
(0.0008)\end{array}$ & $\begin{array}{l}-0.0006^{*} \\
(0.0003)\end{array}$ \\
\hline west & $\begin{array}{l}-0.0044^{* * *} \\
(0.0003)\end{array}$ & $\begin{array}{l}-0.0047^{* * *} \\
(0.0010)\end{array}$ & $\begin{array}{l}-0.0109 * * * \\
(0.0004)\end{array}$ \\
\hline
\end{tabular}


chldnm

Ifp_res_hat

_cons

$\mathrm{N}$ (unwieghted)

Adjusted R2

\section{$-0.0006 * * *$}

(0.0001)
$1.4124 * * *$
(0.2130)
$0.2236 *$
(0.1344)
$17,733,495$
0.2647

$-0.6677 * * *$

(0.0016)

(0.0017)

$17,733,495$

Notes: *** indicates significant at the $1 \%$ level; ** 5\%; * 10\%. Robust standard errors are in parentheses. Sample contains individuals aged 16+. Dec. 2007 is omitted.

\subsection{Adjusted vs. Observed EPOP}

The implication for removing the omitted variable bias from the coefficient estimates on the month/year indicators can be seen in Figure 4, which plots the month/year coefficients from estimating equation (3') (the solid black line), which, recall, matches the actual EPOP statistic reported by the BLS; the month/year coefficients from estimating equation (6), excluding $L \widehat{F P \_} R_{i t}$ (the solid gray line); and the month/year coefficients from estimating the fully specified equation (6) (the black dashed line). All three sets of coefficients are anchored at December 2007, the peak of the previous business cycle (i.e., the month/year indicator excluded from the estimation corresponds to December 2007).

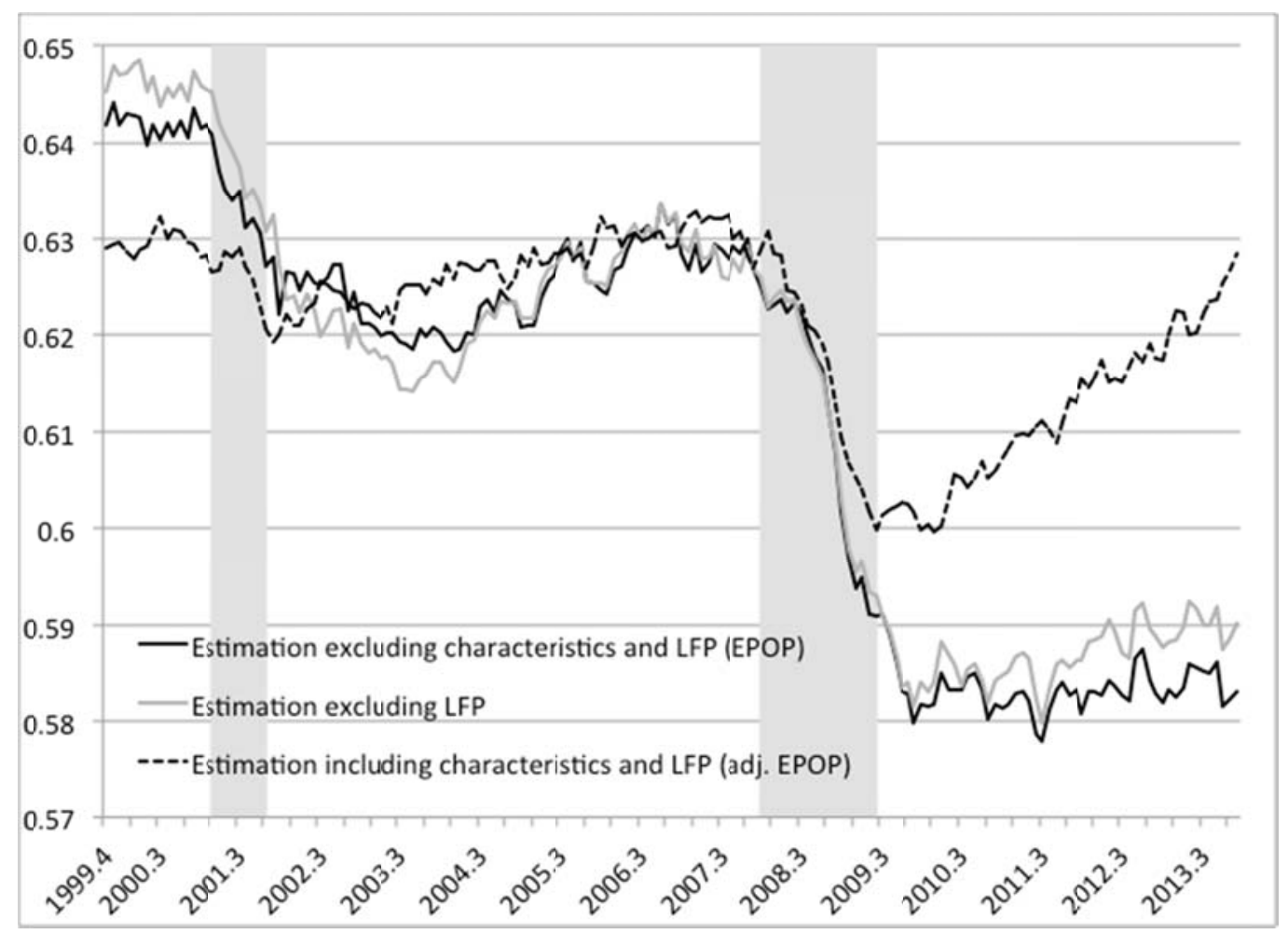

Figure 4. Probability of Employment Estimates for Different Model Specifications

Notes: Population 16-plus years. Gray bars reflect recessionary periods. Point of reference (excluded month/quarter from estimation) is December 2007, the peak of the previous business cycle. 
Note that when the probability of labor force participation is excluded from the estimation of the joint employment/LFP outcome, relatively low probabilities of labor force participation in any given month/year (i.e., $\operatorname{Corr}\left[m y_{t}, e_{i t}\right]<0$ in equation $3^{\prime}$ ) will pull down employment, biasing that coefficient, $\hat{\delta}_{t}$, as an indicator of the average employment outcome, downward. Removing the confounding influence of the probability of labor force participation reveals that the population employment probability (adjusted EPOP) has risen to its prerecession level of 62.8 percent. Note that inclusion of the probability of labor force participation has a greater influence on the estimated month/year coefficients than merely including controls for demographics. This suggests that individual behavior changed more dramatically over this time period than did demographics of those participating in the labor force. (Note 14)

Figure 5 compares this adjusted EPOP to the movement in the ER (one minus $U R$ ), illustrating what we already knew - the stagnation observed in the EPOP derives from the ongoing declines in labor supply behavior. However, without the adjusted EPOP, it was unclear how much of that stagnation resulted from labor supply behavior and how much derived from a weak labor market. Figures 4 and 5 tell us that pretty much all of the stagnation in EPOP is the result of changing labor supply. Also, note that the adjusted EPOP does not merely replicate the movement in the $E R$ - the fall in the ER prior to the 2001 recession is steeper and deeper than the fall in the adjusted EPOP, and the rise in the $E R$ post-Great Recession is (slightly) steeper than the rise in the adjusted EPOP.

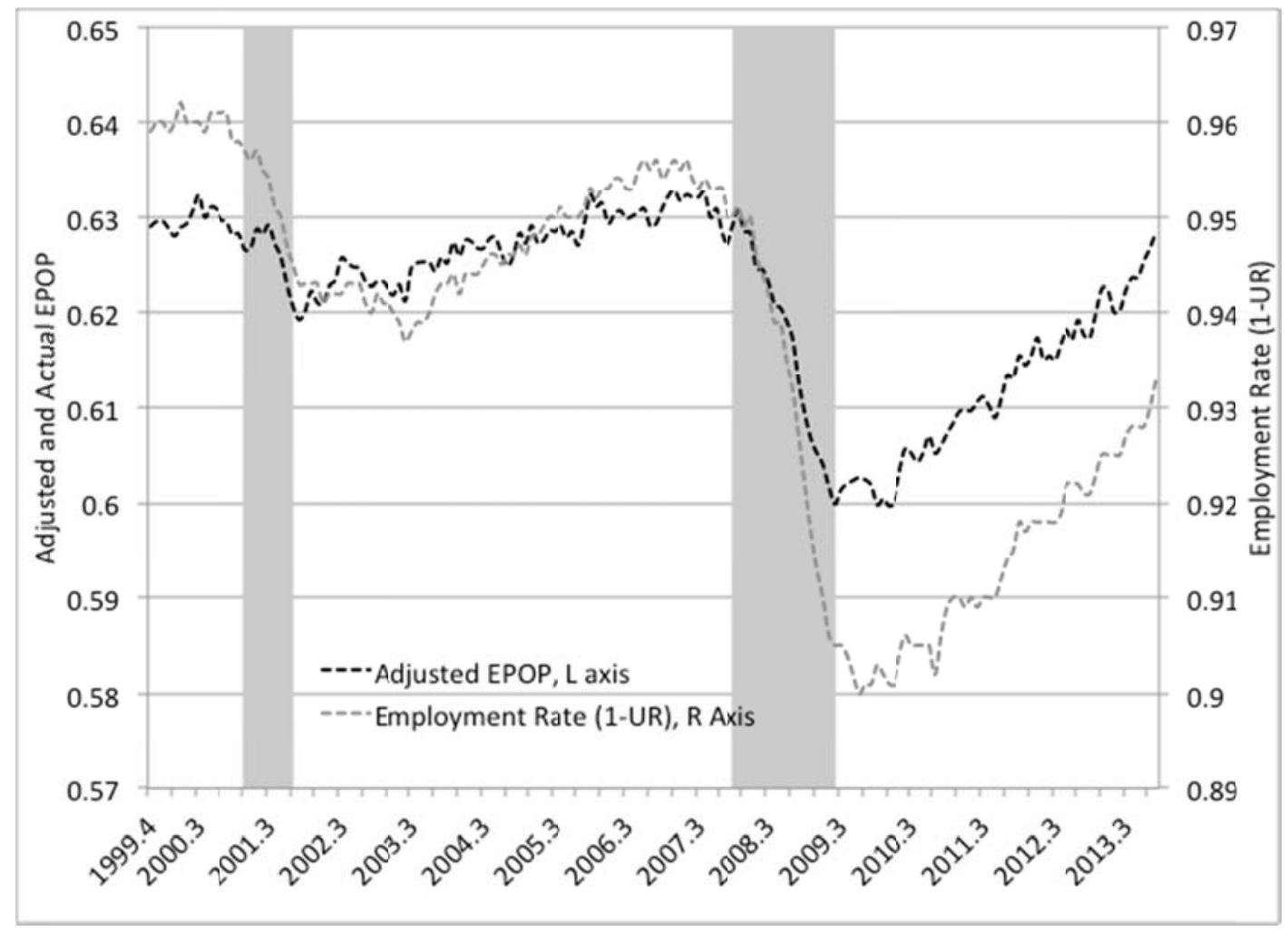

Figure 5. Adjusted EPOP and the ER (1-UR)

Notes: Population 16-plus years. Gray bars reflect recessionary periods. Point of reference (excluded month/quarter from estimation) is December 2007, the peak of the previous business cycle. 


\subsection{Adjusted EPOP by Age and Education}

While on average the population may have achieved its prerecession probability of employment, there may be some heterogeneity in experience by characteristics, such as age and education. The analysis above was repeated for three age groups (16-24, 25-54, and $55+$ ) and two education groups, those with a high school degree only and those with at least a college degree. While there are some relatively minor differences in experience, all groups compared have either regained all of their loss in employment probability or nearly regained all of their loss.

Figure 6 illustrates that not only did those with only a high school degree experience a greater loss in employment probability during the Great Recession than those with at least a college degree (3pp vs. 2pp), they also have not regained as much of their loss. High school grads have regained 41 percent of their employment probability loss whereas college graduates have regained 53 percent of their loss.

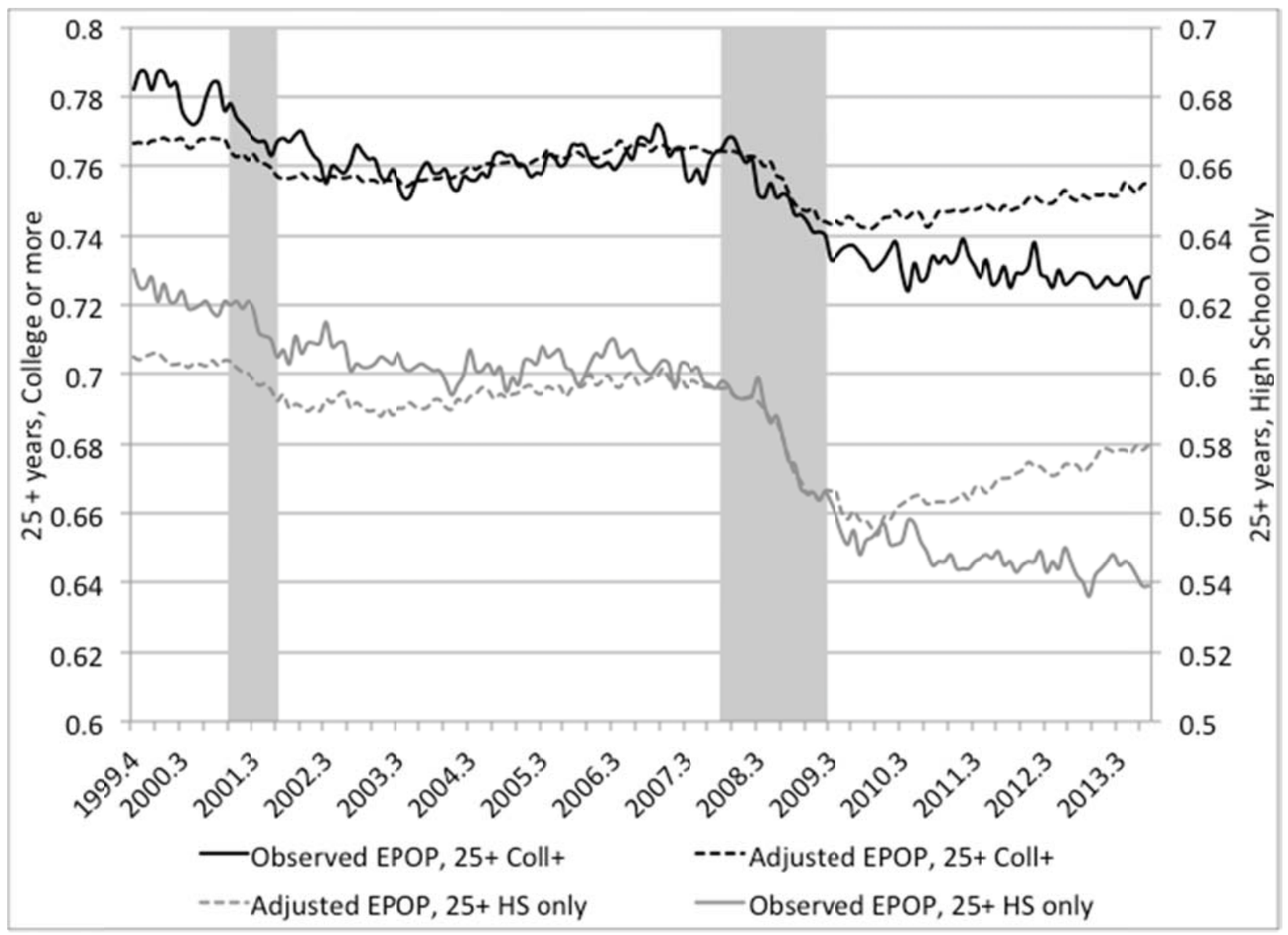

Figure 6. Observed and Adjusted EPOP for Those 25 Years and Older, by Education Level.

Notes: Gray bars reflect recessionary periods. Point of reference (excluded month/quarter from estimation) is December 2007, the peak of the previous business cycle.

In spite of the dismal picture we might have of youth employment prospects (or, maybe, because of it, see, for example, Fogg and Harrington 2011 and Wirtz 2007), Figure 7 illustrates that those aged between 16 and 24 have regained more of their steep drop in employment probability experienced during the Great Recession than those aged 25 to 54 or 
those 55 and older. The youth have regained 144 percent of their drop, whereas 25- to 54-year-olds and those 55 and older have regained 71 percent and 46 percent of their losses, respectively.

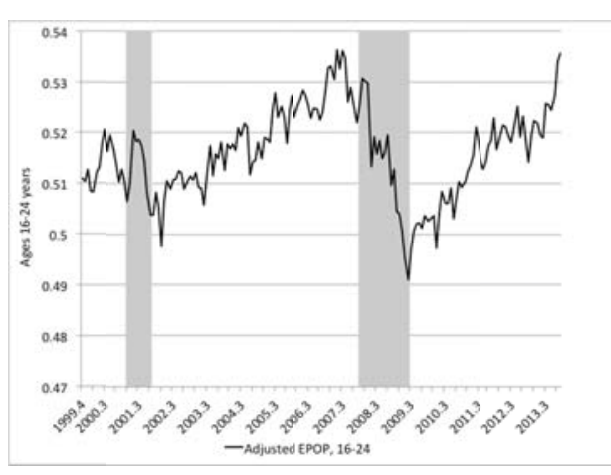

Panel (a): Ages 16-24

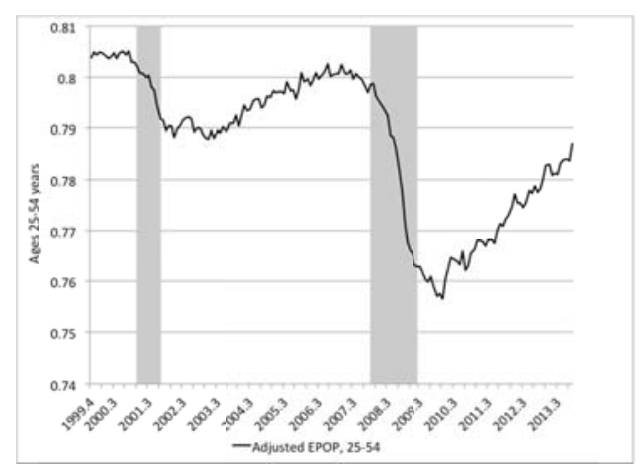

Panel (b): Ages 25-54

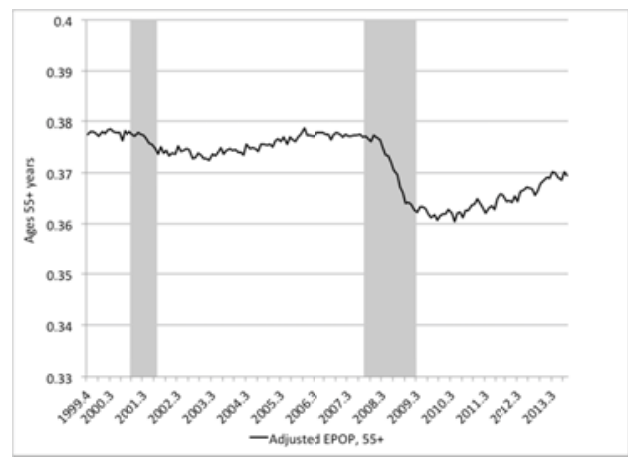

Panel (c): Ages 55+

Figure 7. Adjusted EPOP by Different Age Groups

Notes: Gray bars reflect recessionary periods. Point of reference (excluded month/quarter from estimation) is December 2007, the peak of the previous business cycle.

\section{Conclusions}

There is likely universal agreement that the most important measure of a strong labor market is employment growth. But how much employment growth is sustainable and necessary for attaining maximum employment? By focusing on the raw employment-to-population ratio (EPOP), some appear to be arguing that the strength of employment growth should be gauged by whether some undefined share of the population is employed; this leaves open the question of what that share should be-anyone in the population group, or anyone in the population group who wants a job (labor force participants)?

This paper proposes a methodology for adjusting the EPOP to account for labor force participation decisions. The adjusted EPOP offers a measure of employment outcomes, unconfounded by labor supply behavior. The adjusted EPOP presented here confirms what we already knew - that the stagnation of the EPOP since the end of the Great Recession is the result of continued declines in the labor force participation rate. However, by stripping the EPOP of confounding changes in labor supply we uncover a story that is more consistent with what movements in the $U R$ have been telling us-the adjusted EPOP has regained its prerecession level of nearly 63 percent. Youth have regained even more, and those 25 to 54 regained 71 percent of their loss over the sample period. As a point of reference, by the end of 2013 the UR had recovered roughly 66 percent of the climb to its peak of 10 percent.

Of course, there remains the issue of declining labor force participation. This is a legitimate but different concern than whether the labor market is providing enough jobs. (Note 15) As fewer people want to participate in the labor market, or as population growth slows, the economy potentially runs into problems fueling desired economic growth. (Note 16) In addition, the question of underemployment has been raised. Whereas the adjusted EPOP (and 
$U R$ for that matter) treats all jobs the same, the elevated level of workers who are employed part-time but would like a full-time job (i.e., part-time for economic reasons) reminds us that not all jobs are created equal. In other words, if all workers were involuntarily part-time employed, the resulting adjusted EPOP of 100 percent would be masking a significant underutilization of human resources (for example, see Altig 2014, Robertson 2014a, and Valletta and Bengali 2013).

\section{Acknowledgement}

The views expressed here are those of the author and not necessarily those of the Federal Reserve Bank of Atlanta or the Federal Reserve System. Comments by Christopher Cunningham, Timothy Dunne, Patrick Higgins, M. Melinda Pitts, and John C. Robertson are gratefully acknowledged. Excellent research assistance was provided by Yanling Qi.

\section{References}

Aaronson, Daniel, Jonathan Davis, \& Luojia Hu. (2012). Explaining the Decline in the U.S. Labor Force Participation Rate. Chicago Fed Letter (March 2012). Retrieved 6/6/14 from

http://www.chicagofed.org/webpages/publications/chicago_fed_letter/2012/march_296. $\mathrm{cfm}$

Albanesi, Stefania, Aysegul Sahan, \& Joshua Abel. (2012). Reconciling Signals in the Labor Market: The Role of Participation. Liberty Street Economics (March 30, 2012). Retrieved 4/20/14 from http://libertystreeteconomics.newyorkfed.org/2012/03/reconciling-contrasting-signals-in -the-labor-market-the-role-of-participation.html\#.U1Jp0UTGtgh

Altig, Dave. (2012). A Take on Labor Force Participation and the Unemployment Rate. Macroblog (May 10, 2012). Retrieved 4/23/14 from http://macroblog.typepad.com/macroblog/2012/05/a-take-on-labor-force-participation-a nd-the-unemployment-rate.html

Altig, Dave. (2014). Thinking about Progress in the Labor Market. Macroblog (March 7, 2014). Retrieved $4 / 23 / 14$ from http://macroblog.typepad.com/macroblog/2014/03/thinking-about-progress-in-the-labormarket.html

Anderson, Richard G. (2012). How Positive Are Recent Employment and Labor Market Trends? Federal Reserve Bank of St. Louis Economic Synopses (September 14, 2012). Retrieved 4/23/14 from http://research.stlouisfed.org/publications/es/article/9436

Angirst, Joshua D., \& Jorn-Steffen Pishke. (2009). Mostly Harmless Econometrics: An Empiricist's Companion. Princeton, N.J.: Princeton University Press. 
Bivens, Josh. (2014). Overall Employment to Population Ratio: Not the Best Summary Indicator, but Not That Misleading, Either. Economic Policy Institute Blog. (February 3, 2014). $\quad$ Retrieved 4/20/14 from http://www.epi.org/blog/employment-population-ratio-summary-indicator/

Caudill, Steven B. (1988). An Advantage of the Linear Probability Model over Probit or Logit. Oxford Bulletin of Economics \& Statistics, 50(4), 425-7. http://dx.doi.org/10.1111/j.1468-0084.1988.mp50004005.x

Fogg, Neeta P., \& Paul E. Harrington. (2011). The Collapse of the Labor Market for 16- to 24-Year-Olds. Federal Reserve Bank of Philadelphia Cascade 78 (Fall 2011). Retrieved from

$4 / 23 / 14$ http://www.philadelphiafed.org/community-development/publications/cascade/78/04_co llapse-of-16-to-24-labor-market.cfm

Hartley, Daniel. (2011). The Labor Force: To Work or Not to Work. Federal Reserve Bank of Cleveland Forefront (November 8, 2011). Retrieved 4/23/14 from http://www.clevelandfed.org/forefront/article.cfm?a=11862

Heckman, James J. (1979). Sample Selection Bias as a Specification Error. Econometrica 47(1), 153-61. http://dx.doi.org/10.2307/1912352

Higgins, Pat. (2014). A Second Look at the Employment-to-Population Ratio. Macroblog (February 11, 2014). Retrieved 4/23/14 from http://macroblog.typepad.com/macroblog/2014/02/a-second-look-at-the-employment-topopulation-ratio.html?d=1\&s=hcc

Hotchkiss, Julie L. (2004). A Closer Look at the Employment Impact of the Americans with Disabilities Act. Journal of Human Resources, 39(Fall 2004), 887-911. http://dx.doi.org/10.2307/3559031

Hotchkiss, Julie L., \& Robert E. Moore. (1999). On the Evidence of a Working Spouse Penalty in the Managerial Labor Market. Industrial and Labor Relations Review, 52, 410-23. http://dx.doi.org/10.2307/2525142

Hotchkiss, Julie L., \& Fernando Rios-Avila. (2013). Identifying Factors in the Decline the U.S. Labor Force Participation Rate. Business \& Economic Research, 3(1), 257-75.

Kapon, Samuel \& Joseph Tracy. (2014). A Mis-Leading Labor Market Indicator. Liberty Street Economics (February 3, 2014). Retrieved 4/20/14 from http://libertystreeteconomics.newyorkfed.org/2014/02/a-mis-leading-labor-market-indic ator.html\#.U1RucmiYbv5

Kudlyak, Marianna \& Fabian Lange. (2014). Measuring Heterogeneity in Job Finding Rates among Those out of the Labor Force. Paper presented at the Applied Micro Conference, Minneapolis, MN (May 2014).

Lazear, Edward P. (2014). The Hidden Jobless Disaster. WSJ.com (June 5, 2013). Retrieved 
$4 / 20 / 14$

from http://online.wsj.com/news/articles/SB1000142412788732372820457851418332317167 0

Matheny, Kenneth J. (2009). Trends in the Aggregate Labor Force. Federal Reserve Bank of St. Louis Review, 91(4), 297-309.

McCarthy, Jonathan \& Simon Potter. (2012). Prospects for the U.S. Labor Market. Liberty Street Economics (March 26, 2012). Retrieved 4/20/14 from http://libertystreeteconomics.newyorkfed.org/2012/03/prospects-for-the-us-labor-market .html\#.U1JtKGiYbv4

Mroz, Thomas A., \& Yaraslau V. Zayats. (2008). Arbitrarily Normalized Coefficients, Information Sets, and False Reports of 'Biases' in Binary Outcome Models. Review of Economics and Statistics, 90(3), 406-13. http://dx.doi.org/10.1162/rest.90.3.406

Pitts, M. Melinda, John C. Robertson, \& Ellyn Terry. (2014). Reasons for the Decline in Prime Age Labor Force Participation. Macroblog (April 10, 2014). Retrieved 4/23/14 from

http://macroblog.typepad.com/macroblog/2014/04/reasons-for-the-decline-in-prime-agelabor-force-participation-.html

Robertson, John C. (2014a). A Football Field of Labor Market Progress. Macroblog (January 14, 2014a). Retrieved 4/23/14 from http://macroblog.typepad.com/macroblog/2014/01/a-football-field-of-labor-market-prog ress.html

Robertson, John C. (2014b). A Prime-Aged Look at the Employment-to-Population Ratio. Macroblog (February 6, 2014b). Retrieved 4/23/14 from http://macroblog.typepad.com/macroblog/2014/02/a-prime-aged-look-at-the-employmen t-to-population-ratio.html

Shierholz, Heidi. (2014). My Favorite Measure of Labor Market Health Is Looking a Little Better. Economic Policy Institute Blog (February 7, 2014). Retrieved 4/20/14 from http://www.epi.org/blog/favorite-measure-labor-market-health/

Trasci, Murat \& Beth Mowry. (2009). Alternative Measures of the Unemployment Rate. Federal Reserve Bank of Cleveland Economic Trends (October 7, 2009). Retrieved 4/23/14 from http://www.clevelandfed.org/research/trends/2009/1109/01ecoact.cfm

Valletta, Rob \& Leila Bengali. (2013). What's Behind the Increase in Part-Time Work? Federal Reserve Bank of Atlanta Economic Letter (August 26, 2013). Retrieved 4/23/24 from http://www.frbsf.org/economic-research/publications/economic-letter/2013/august/part-t ime-work-employment-increase-recession/

Wirtz, Ronald A. (2007). OMG! Like, Where Are All the Teen Workers? Federal Reserve Bank of Minneapolis FedGazette (September 2007): 7-11. Retrieved 4/23/14 from 
http://www.minneapolisfed.org/pubs/fedgaz/09-09/teenlabor.pdf

Wooldrige, Jeffrey M. (2010). Econometric Analysis of Cross Section and Panel Data (2nd ed.). Cambridge, MA: The MIT Press, 2010.

\section{Notes}

Note 1. See Bivens (2014), Shierholz (2014), Lazear (2013), Albanesi et al. (2012), and Trasci and Mowry (2009). An alternate view of the usefulness of EPOP as an indicator of labor market strength after the Great Recession is offered by Kapon and Tracy (2014).

Note 2. Discussion of the usefulness of the EPOP as a measure of labor utilization can be found in Robertson (2014b).

Note 3. See McCarthy and Potter (2012) for how the pieces of this decomposed EPOP have evolved over previous recessions and recoveries.

Note 4. Using appropriate statistical corrections for selection into the labor market (e.g., Heckman 1979), one can generate a population estimate from modeling the $E R$. In addition, one could think about modeling EPOP as a problem of censored data (independent variables are observed for all observations, but the dependent variable, employment, is only observed for those in the labor force), whereas modeling $E R$ can be thought of as a problem of truncated data (both independent and dependent variables are only observed for those in the labor force).

Note 5. Indeed, in his seminal solution for obtaining population estimates from a selected sample, Heckman (1979) frames the problem as one of omitted variable bias.

Note 6. Concerns have been raised about the accuracy of responses to questions in the CPS used to classify a person's labor market status (see Kudlyak and Lange 2014). All the analysis in this paper assumes that an individual's labor market status is accurately recorded.

Note 7. The desire to deseasonalize individual employment outcomes means that estimating the employment equation via OLS as a linear probability model, as opposed to as a probit or logit, is preferred; the deseasonalized value of $E M P_{i t}$ takes on values other than zero and one. For additional advantages of linear probability estimation, generally, over probit or logit, see Angrist and Pischke 2009, pp. 197-8; Mroz and Zayats 2008; and Caudill 1988.

Note 8. The suggestion of this robustness check made by Patrick Higgins is gratefully acknowledged.

Note 9. The suggestion of this approach made by Chris Cunningham is gratefully acknowledged.

Note 10. Higgins (2014) illustrates the importance of controlling for demographics in assessing the movement of the EPOP. See Wooldrige (2010: pp. 65-72) for a thorough treatment of omitted variable bias. 
Note 11. An alternative empirical approach would be to model employment and labor force participation as a bivariate probit with selection (see Hotchkiss 2004), or as a Heckman (1979) selection model (for the linear equivalent). This approach, however, is akin to modeling the employment ratio $(E R)$ (one minus the unemployment ratio), rather than EPOP.

Note 12. It would be possible to match spouses in the monthly CPS in order to at least control for spouse's income, but in order to be useful, we are trying to keep the process as simple as possible while maintaining the integrity of the estimation. There is a control for marital status in the labor force participation equation, but it is also used as a regressor in the employment equation, as others have shown it to be important in the determination of market wage (e.g., see Hotchkiss and Moore 1999).

Note 13. In order for $\widehat{L F P}_{i t}$ to be a consistent proxy for $L F P_{i t}^{*}$, we must assume that $\widehat{L F P}_{R_{i t}}$ is redundant (or ignorable) in the employment equation if we were able to include $L F P_{i t}^{*}$, and that once the proxy is controlled for, $m y_{t}$ are no longer correlated with $L F P_{i t}^{*}$; in other words, $\operatorname{Corr}\left[m y_{t}, v_{i t}\right]=0$.

Note 14. An analogous estimation (not shown here, but available upon request) of the employment rate $(E R)$, which reflects employment outcomes conditional on labor force participation, shows that impact in Figure 4 of including demographics derives from changes in demographics of labor force participants, rather than changes in demographics of those who are employed.

Note 15. There has been much discussion about cyclical versus structural changes in the $L F P R$ and the implications of those changes for assessing labor market strength and labor utilization. For example, see Pitts et al. (2014), Hotchkiss and Rios-Avila (2013), Altig (2012), Aaronson et al. (2012), Anderson (2012), and Harley (2011).

Note 16. See Matheny (2009) for how trend growth in labor force participation contributes to estimates of potential GDP growth.

\section{Appendix: Adjusting Weights to Account for Population Growth}

When using population weights in a regression over time, later time periods are weighted more heavily than earlier time periods, simply because of population growth. In order to see whether this influences the results in this paper, the analysis was performed again with weights adjusted so that they sum to the same value in each month. Figure A1 illustrates that doing this has no appreciable impact on the results - the gray dashed line (using adjusted weights) is very close to the black dashed lines (using raw weights). 


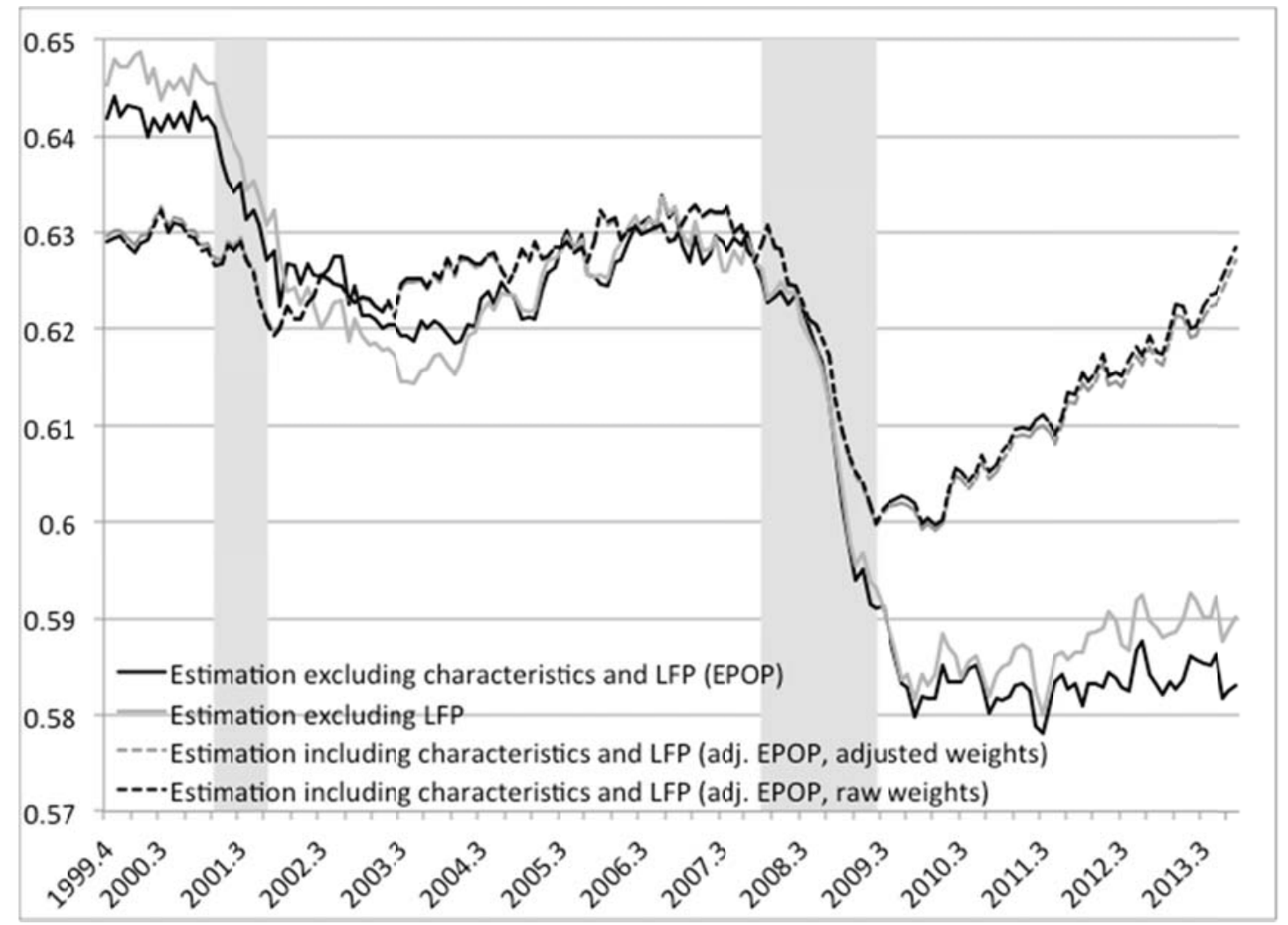

Figure A1. Probability of Employment Estimates Using Different Weights Note: See Chart 4 in text.

\section{Copyright Disclaimer}

Copyright reserved by the author(s).

This article is an open-access article distributed under the terms and conditions of the Creative Commons Attribution license (http://creativecommons.org/licenses/by/3.0/). 